\title{
TOMOGRAPHY IN ARTHRITIS OF THE SMALL JOINTS*
}

\author{
BY \\ G. D. KERSLEY, F. G. M. ROSS, S. J. FOWLES, AND C. JOHNSON \\ United Bristol Hospitals, Bristol Royal Infirmary
}

The value of tomography lies in its ability to disperse the radiographic shadows of anatomical structures and pathological processes which obscure the image of the part it is intended to investigate, while leaving in focus on the radiograph the image of the structures it is desired to show in detail. Tomography has a well-established place in the radiological examination of the larger and denser parts of the body, such as the skull, spine, hips, and chest. It has, however, not proved to be so rewarding in the past when applied to such small and superficial parts as the joints of the hands and feet. This has been largely due to the limitations imposed by the type of tomographic apparatus most frequently used in Great Britain. This utilizes movement of the $x$-ray tube and film in a straight line, a method known as linear tomography, in order to blur out the images of the unwanted structures overlying the plane of section. Unfortunately, when linear tomography is used, the clarity of the radiographs is marred by the production of tomography lines. By moving the $x$-ray tube and film in a circle, a method known as circular tomography, the tomography lines are avoided and the radiographs of the plane of section are therefore much clearer and sharper. More complicated and expensive apparatus is required, however, for circular than for linear tomography.

\section{The Polytome}

The Polytome is a specialized tomographic apparatus which has been described in detail in previous publications (Carter, Martin, Middlemiss, and Ross, 1963; Ross, 1963). It is designed to perform precision tomography with a choice of four different obscuring tube movements, i.e. linear, circular, elliptical, and hypocycloidal, the last being a clover-leaf pattern representing two eccentric

\footnotetext{
* Based on a paper read to the Heberden Society in December, 1963.
}

circles. The image produced on the radiograph is magnified and there is a choice of two constant magnifications, 1.3 and 1.6 times subject size. When the larger magnification is used, the process is called macrotomography and this has proved to be the most suitable method for demonstration of the hands, wrist and feet.

\section{Present Investigation}

Selected joints of the hands, wrists, and feet of a series of some forty patients suffering from typical rheumatoid arthritis, osteo-arthritis, and gout have been examined by serial macrotomography during the last 2 years. The purpose of this paper is to report the findings in these cases.

\section{Findings}

The first thing that became obvious on reviewing these cases was that macrotomography showed up lesions in the bones that had not been visible or were barely visible on the plain radiographs in cases of rheumatoid arthritis and of gout.

Case 1, a 52-year-old woman, had a history of rheumatoid arthritis for 13 months, with an erythrocyte sedimentation rate of $53 \mathrm{~mm} . / \mathrm{hr}$ and haemoglobin 52 per cent. When the wrist was examined, the findings on the plain radiograph were typical of rheumatoid arthritis and the articular cortex of the lower end of the radius and ulna appeared to be intact. Macrotomography, however, showed large areas of destruction with involvement of the articular cortex in both these bones (Fig. 1, opposite).

Case 2, a 48-year-old man, had had typical attacks of gout for 3 years, mostly in the left big toe. His plasma uric acid was $7.5 \mathrm{mg}$. per cent. and the latex-fixation test was negative. The plain radiograph of the right big toe showed minimal changes in the base of the proximal phalanx, but the macrotomograph demonstrated a small area of loss of articular cortex of the phalanx leading into a deeper area of destruction which was surrounded by a fine rim of sclerosis (Fig. 2, opposite). 


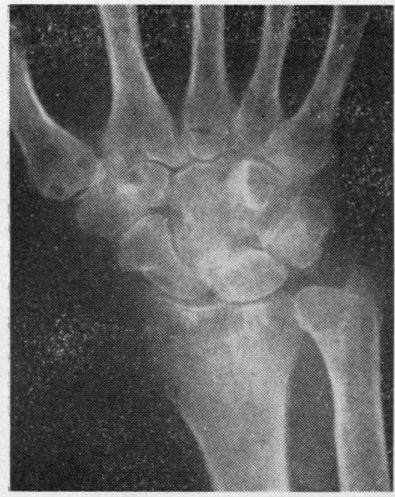

(a)

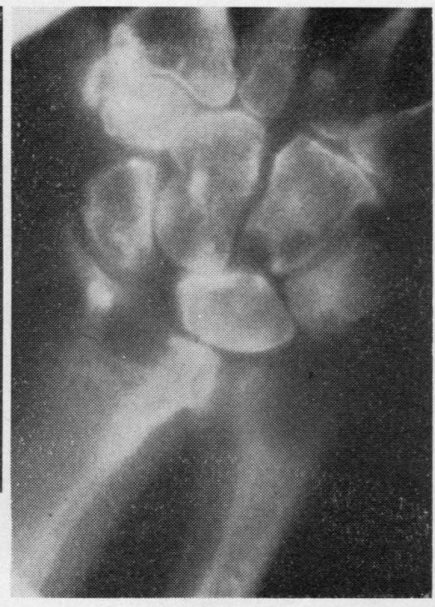

(b)

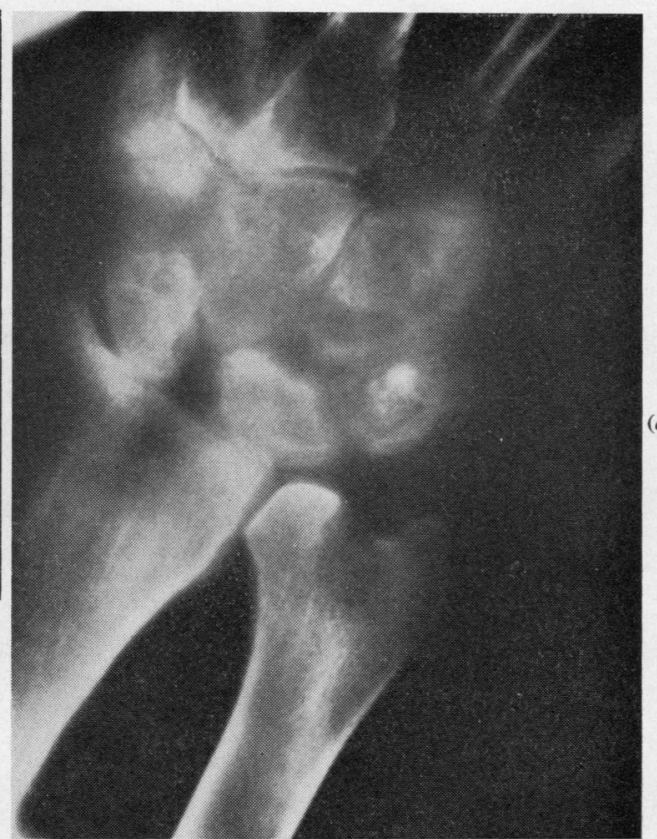

$(c)$

Fig. 1.-Rheumatoid arthritis.

s and erosions, particularly of hamate and thumb metacarpal.

(b) and (c) Macrotomographs at 2.75 and $3.25 \mathrm{~cm}$. Areas of destruction are now visible in lower ends of radius and ulna with destruction of overlying articular cortex. More erosions are shown and also a well-defined sclerotic area in the radius.

Reproduced by permission of the Editor of Clinical Radiology (1963), 14, Fig. 11, p. 412.

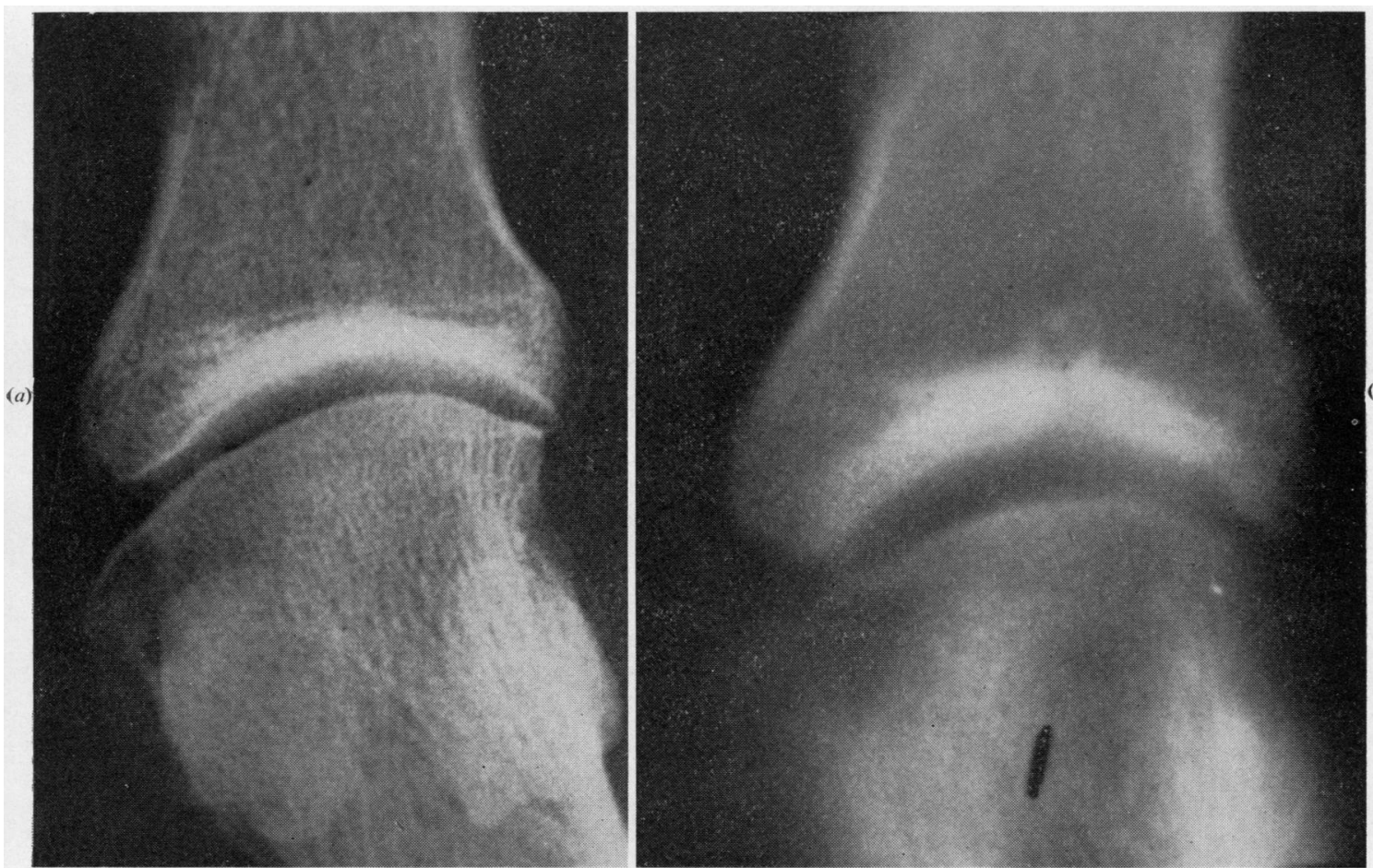

Fig. 2.-Gout (a) Plain radiograph of metatarsophalangeal joint of big toe, showing small ring of sclerosis in centre of base of phalanx. (b) Macrotomograph demonstrating that this ring shadow represents the sclerotic margin of an area of destruction which communicates through the articular cortex with the centre of the joint cavity. 


\section{Rheumatoid Arthritis}

The macrotomographs of the patients with rheumatoid arthritis showed that the majority of the "cysts" seen on the plain radiographs communicated through to the surface of the joint at some point (Figs 1, 4, 5).

A possible exception was Case 3, a woman aged 40 years, who had had a slight polyarthritis for 20 years but who had rapidly developed multiple nodules over the hands and elsewhere only in the last year. In this particular case, no communication to the surface of the joint from the "cysts" in the metacarpals and phalanges was shown by macrotomography (Fig. 3) and it is thought that these "cysts" could be due to true intra-osseous nodules.

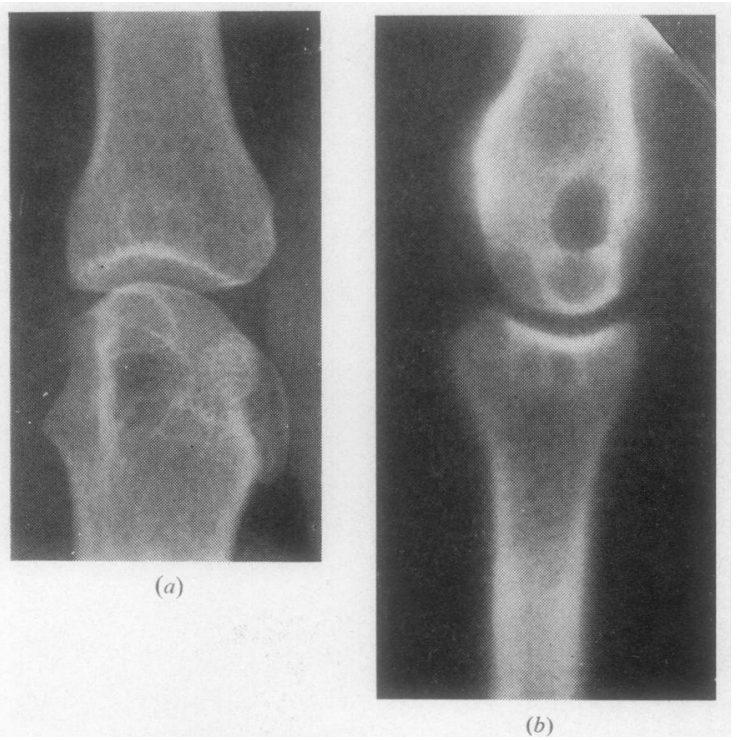

Fig. 3.-Rheunatoid arthritis.

(a) Plain radiograph of ring finger metacarpophalangeal joint, showing "cystic" lesions probably due to nodules in the bone.

(b) Dorsi-palmar macrotomograph showing "cysts" with lateral and articular walls intact.

To be certain of this, good lateral macrotomographs would be necessary and unfortunately these were not obtained. However in all of the seventeen other cases of polyarthritis without multiple nodules examined in this way, breaches cf the wall of apparent "cysts" were demonstrated on the normal dorsipalmer views. In some patients with rheumatoid arthritis retrogression of the lesions under treatment was demonstrated, and in others progression and development of further bony lesions.

Case 4, a 46-year-old man, who had suffered from rheumatoid arthritis for a year when first examined, improved clinically on treatment with hydroxychloro- quine. In this time, macrotomography showed healing of an erosion of the base of the thumb metacarpal and disappearance of osteoporosis of the wrist (Fig. 4, opposite).

Case 5, a 52-year-old woman, who had typical rheumatoid arthritis for a year, an erythrocyte sedimentation rate of $75 \mathrm{~mm} . / \mathrm{hr}$ and a Waaler-Rose titre of 512 was examined over a period of a year. Serial macrotomography of the wrist showed progressive "cyst" formation with destruction of the overlying articular cortex of the radius (Fig. 5, opposite).

\section{OSTEO-ARTHRITIS}

The macrotomographs of the patients with uncomplicated osteo-arthritis were reviewed, and in one a condition radiologically resembling avascular necrosis was seen. In several patients who had "cystic" changes in the bones, the "cysts" were shown to be connected through the articular cortex to the joint and sometimes, even on macrotomography, the resemblance to the appearances seen in rheumatoid arthritis was striking.

Case 6, a 59-year-old woman, had had a sudden onset of pain at the base of the right thumb 5 months before being seen. Plain radiographs showed osteophytosis of the trapezium and metacarpal, while macrotomography demonstrated two dense fragments of bone lying in a defect with a sclerotic margin on the medial side of the metacarpal; 21 months later the two fragments of bone had fused (Fig. 6, overleaf).

Case 7, a 52-year-old man, had had pain in his thumb for 6 months. A plain radiograph showed osteophytosis. and a "cyst" in the base of the thumb metacarpal. Macrotomography demonstrated a connexion between the "cyst" and the joint through the articular cortex (Fig. 7 , overleaf).

Case 8, a 71-year-old woman, had had pain in her thumb for 3 months. The latex-fixation test was negative and no other joints were involved. The plain radiograph showed a translucency in the outer side of the metacarpal, but macrotomography showed that this translucency represented a "cyst" and that there was destruction of the articular cortex over it, an appearance similar to that seen in rheumatoid arthritis (Fig. 8, overleaf).

\section{GouT}

In the cases of gout, examples were seen of "cystic" areas shown on the plain radiograph in which macrotomography demonstrated that they too communicated with the joint cavity through a localized area of destruction of the overlying articular cortex and also regression of the bony lesions was shown accompanying clinical improvement. 

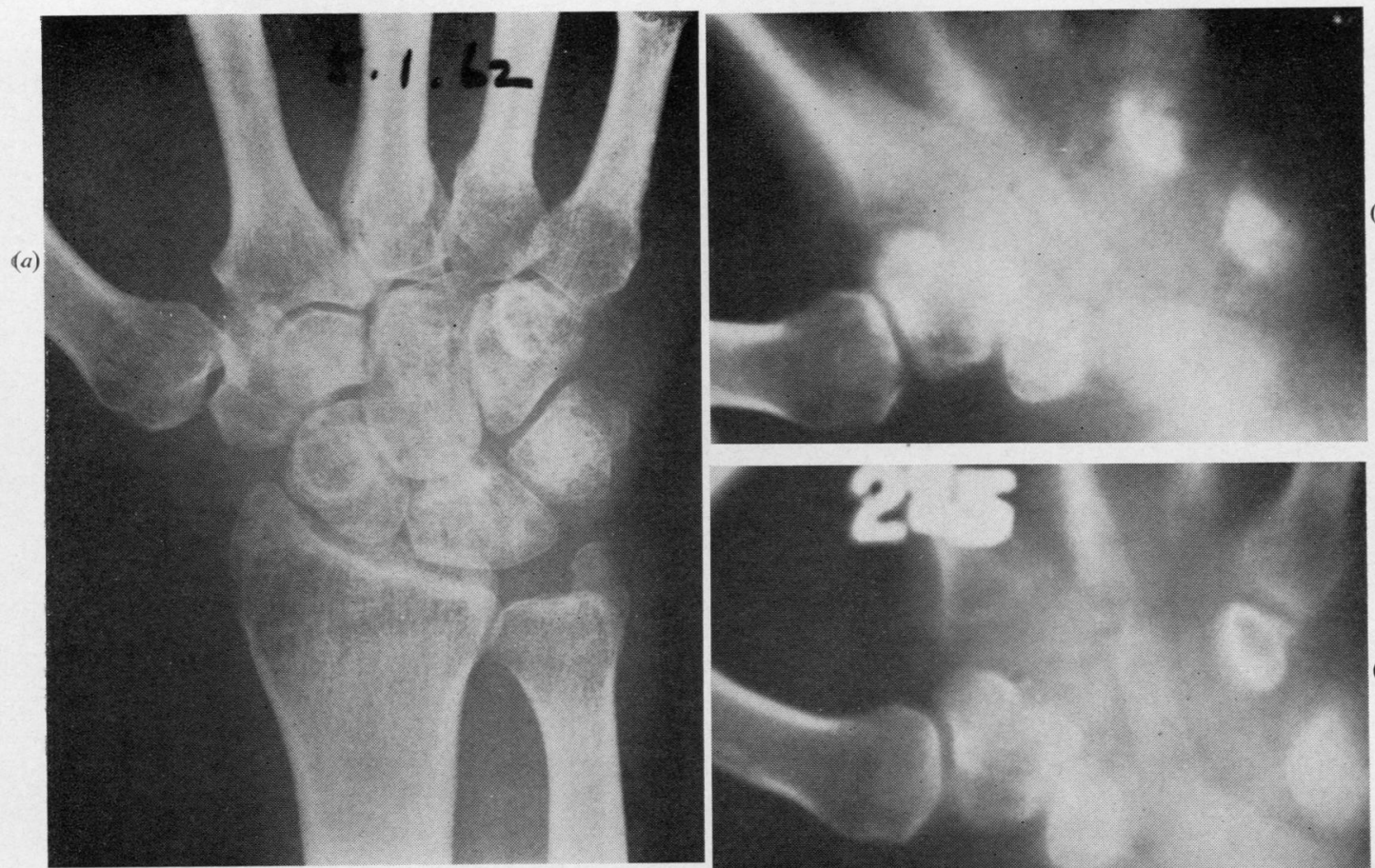

(b)

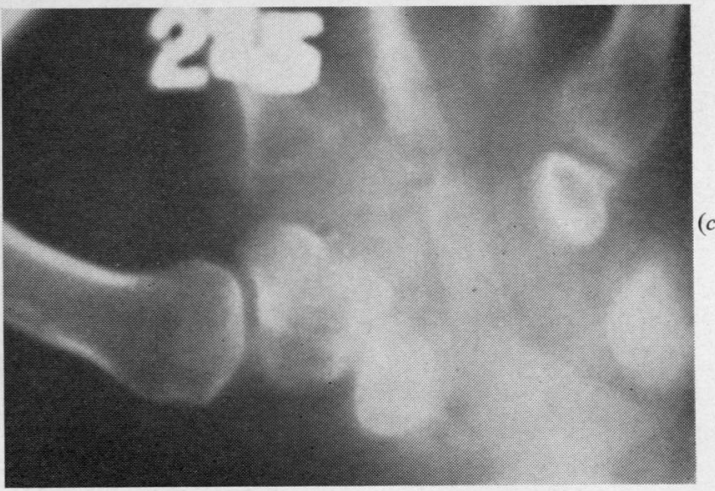

Fig. 4.-Rheumatoid arthritis.

(a) Plain radiograph of wrist, revealing periarticular osteoporosis only.

(b) Macrotomograph on the same day as (a), showing appearances of osteoporosis and also erosions of articular cortex of thumb metacarpal and trapezium.

(c) Macrotomograph of same joint 8 months later. The osteoporosis has resolved and the erosion of the thumb metacarpal has healed. The patient had been treated with hydroxychloroquine with marked clinical improvement.

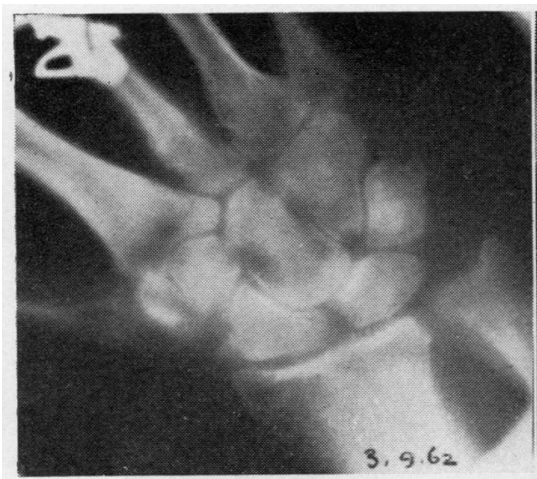

(a)

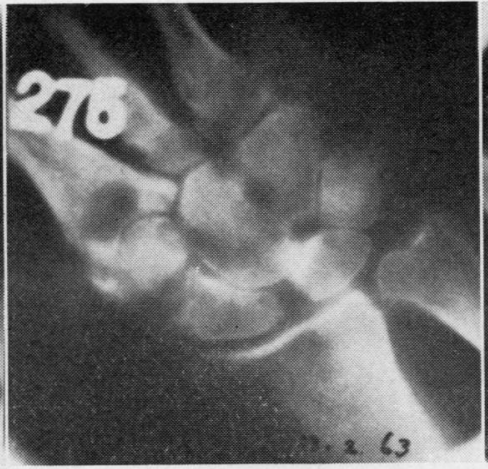

(b)

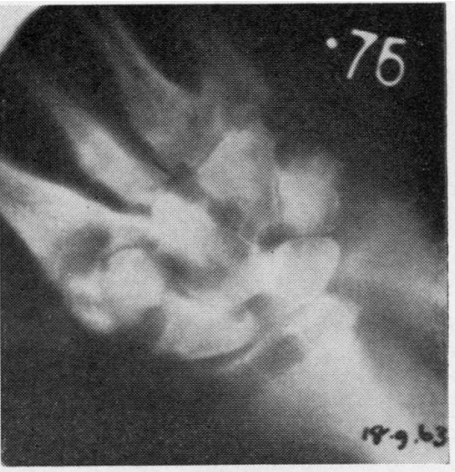

(c)

Fig. 5.-Rheumatoid arthritis.

Macrotomographs of wrist $(a)$ 3.9.62 (b) 13.2.63 (c) 18.9.63, showing progressive destruction in lower end of radius and overlying articular cortex. Multiple erosions are present and there is also progressive cartilage loss particularly between the capitate, hamate, and triquetral with some sclerosis. 

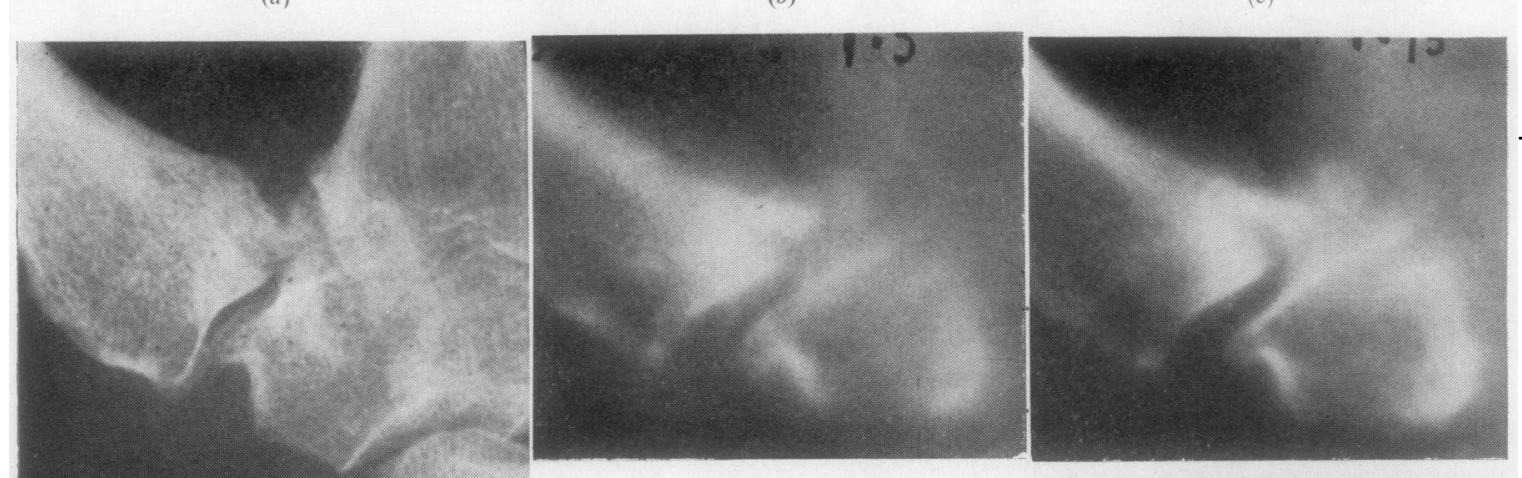

Fig. 6.-Osteo-arthritis.

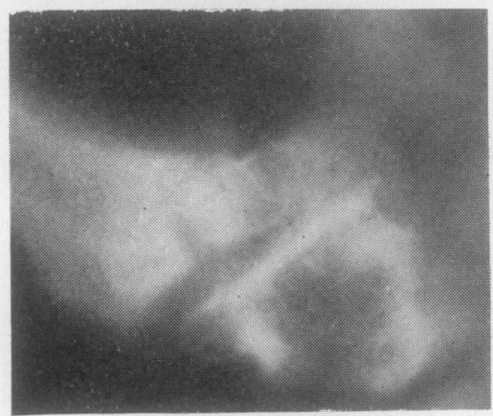

(a) Plain radiograph of thumb metacarpocarpal joint, showing osteophyte on medial side of metacarpal.

(b) and (c) Macrotomographs at 1.5 and $1.75 \mathrm{~cm}$., showing a defect in the medial side of the base of the metacarpal with two small dense bone fragments lying in it.

(d) Macrotomograph 21 months later. The two fragments of bone medially have now united into a single fragment, but they have not fused with the metacarpal.

(a), (b), (c) Reproduced by permission of the Editor of Clinical Radiology (1963), 14, Fig. 10, p. 412.

$(d)$
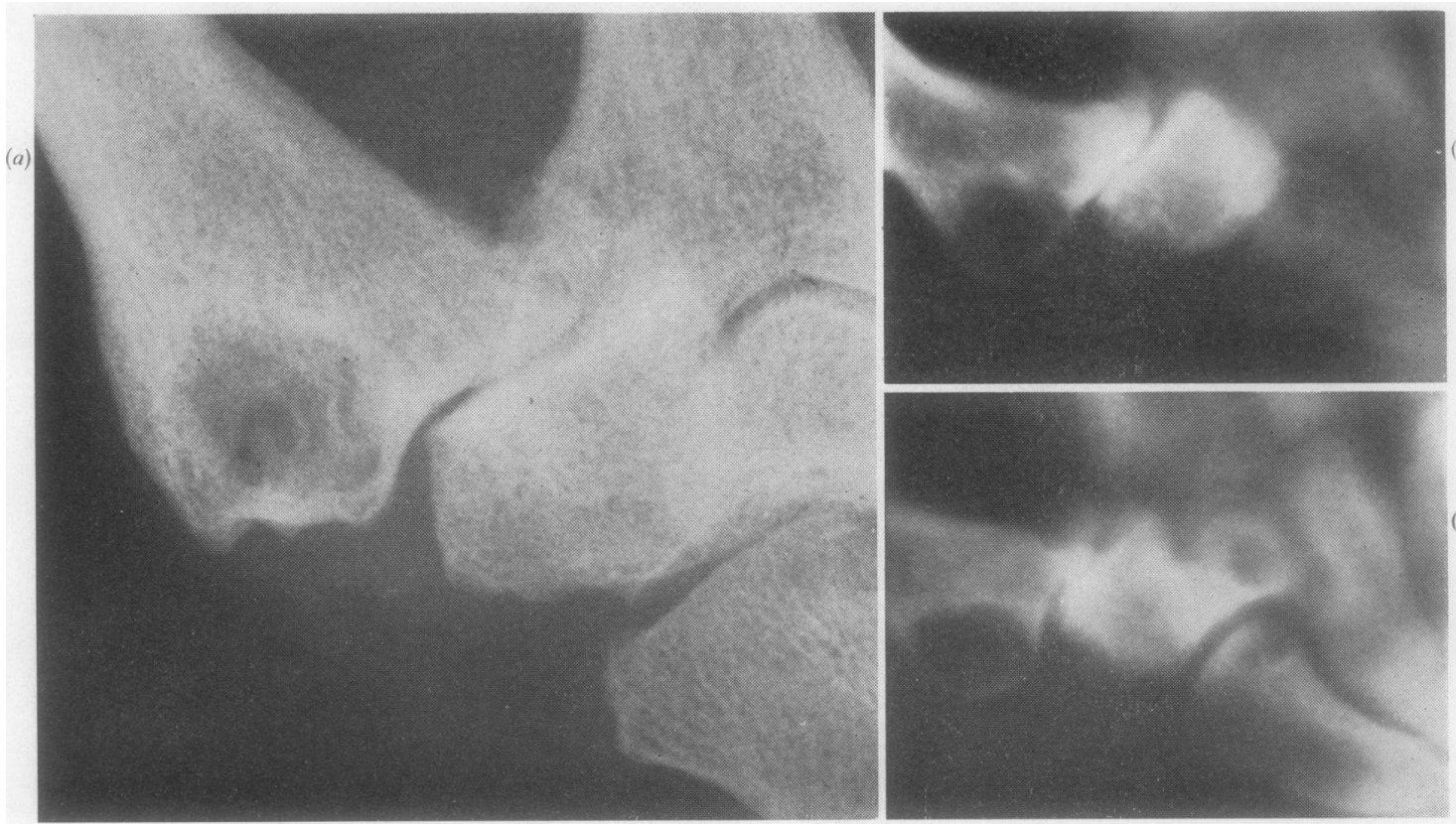

Fig. 7.--Osteo-arthritis.

(a) Plain radiograph of thumb metacarpocarpal joint, showing large "cyst" in metacarpal, loss of joint cartilage, subluxation, and osteophyte on medial side of metacarpal.

(b) Macrotomograph at $2 \mathrm{~cm}$., showing same features more clearly, and in addition destruction of articular cortex over "cyst".

(c) Macrotomograph at $2.5 \mathrm{~cm}$., showing "cyst" outline even more clearly, but destruction of articular cortex is no longer visible. 

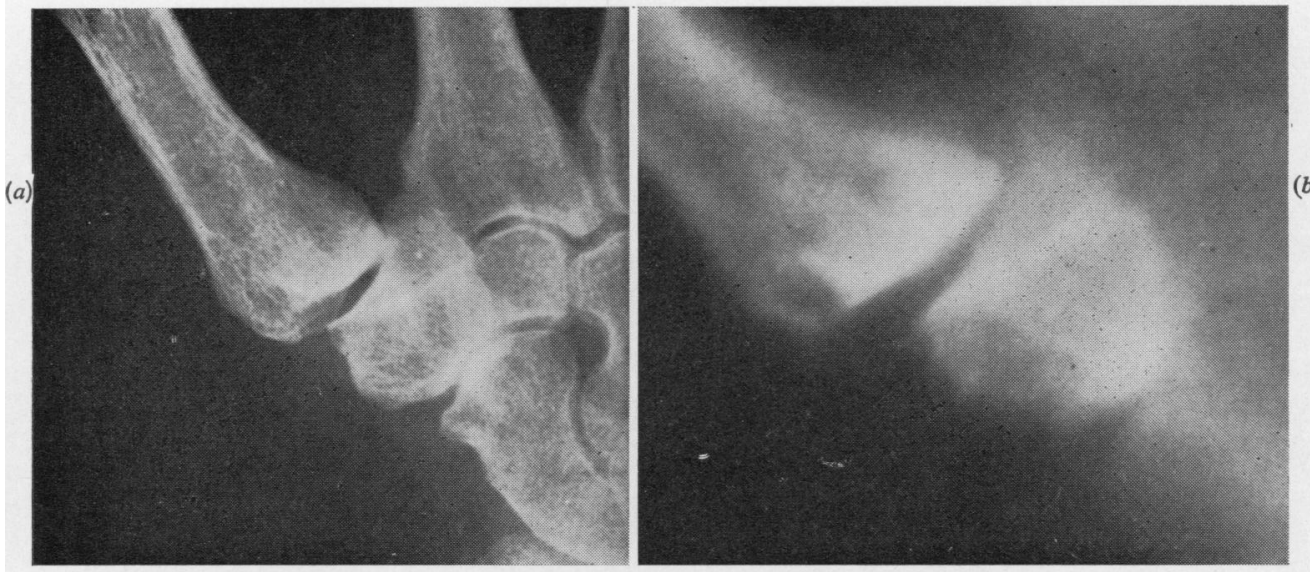

(b)

Fig. 8.-Osteo-arthritis.

(a) Plain radiograph of thumb metacarpocarpal joint, showing small translucency over outer side of metacarnal. (b) Macrotomograph, showing that this translucency represents a "cyst" and that the articular cortex over it is destroyed.

Case 9, a 42-year-old man, had suffered from gout for 21 years. His plasma uric acid was $7 \cdot 3 \mathrm{mg}$. per cent. and the latex-fixation test was negative. Multiple areas of destruction with sclerotic margins were seen in the bones of the wrist on the plain radiograph, and the macrotomographs showed extensive destruction of the articular cortex over these lesions (Fig. 9).
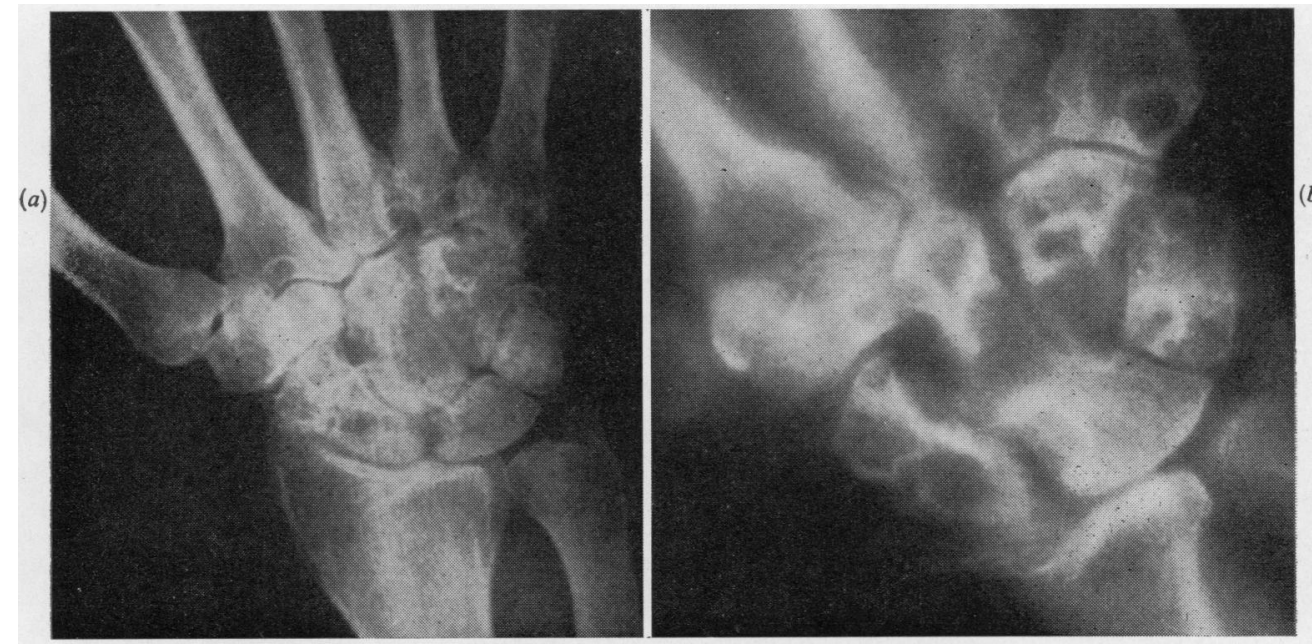

(b)

Fig. 9.-Gout.

(a) Plain radiograph of wrist, showing multiple areas of destruction of metacarpal and carpal bones.

(b) Macrotomograph showing the areas of cortical and medullary destruction with sclerotic margins much more clearly. 
Case 10, a 54-year-old man, with a plasma uric acid of $6.4 \mathrm{mg}$. per cent. and negative latex-fixation test, showed destruction of the articular cortex and subcortical bone of the centre of the base of the proximal phalanx of the left big toe which was not visible on the plain radiograph. 18 months later, after treatment with Anturan had been followed by clinical improvement, re-examination showed that this lesion had nearly healed (Fig. 10).

\section{Discussion}

In general, it may be said that macrotomography of the small joints in patients with arthritis is of value to demonstrate:

(1) Areas of cortical destruction, provided that the involved cortex is perpendicular, or nearly perpendicular, to the plane of section.

(2) Areas of destruction and sclerosis in the medulla of the bones forming the joint.

(3) Loss of joint cartilage.

(4) Separated bone fragments.

In this series of cases, the following features have been demonstrated by macrotomography:
In Rheumatoid Arthritis.-Destruction of the articular cortex over "cystic" areas, erosions not visible on the plain radiographs, and healing of erosions.

In Osteo-arthritis.-Similar destruction of the articular cortex over intramedullary "cysts", sometimes identical to those seen in patients with rheumatoid arthritis, and also lesions resembling avascular necrosis.

In Gout.-Destruction of the articular cortex in the centre of the joint continuous with destruction of subcortical bone, and regression of these lesions accompanying clinical improvement on Anturan treatment.

Probably the greatest value of macrotomography is that experience of the tomographic appearances allows a more accurate interpretation to be made of the features shown on the plain radiograph. With further experience it should help with the earlier diagnosis of doubtful cases and, in conjunction with the clinical picture and morbid histology, it may assist in the understanding of the arthritic processes. (a)

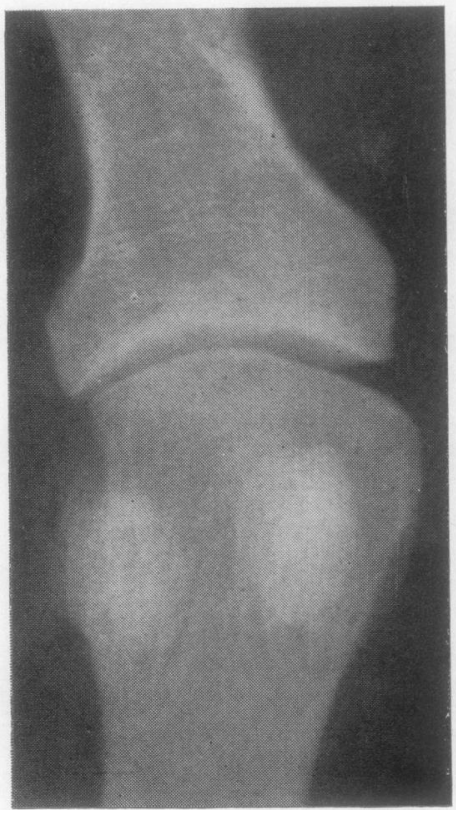

(b)

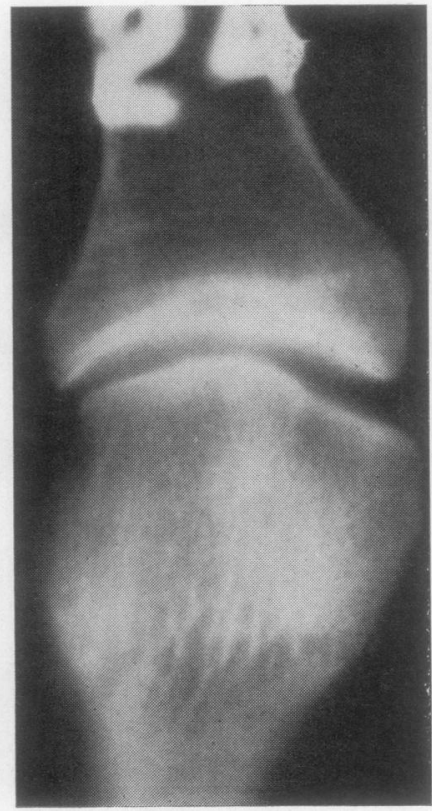

Fig. 10.-Gout. (c)

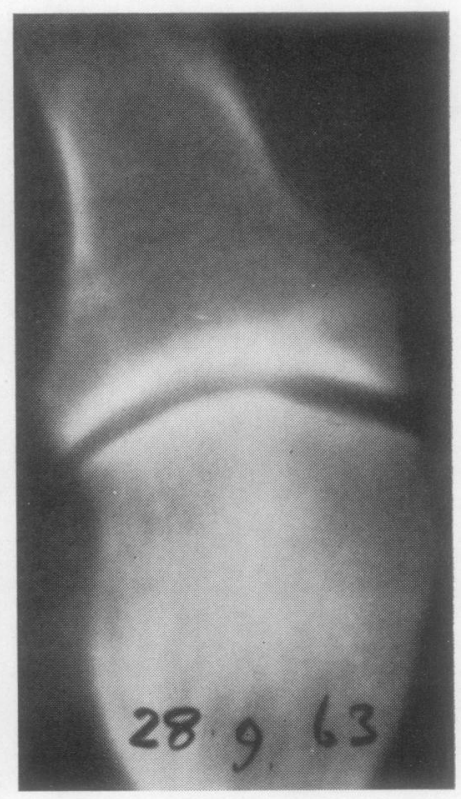

(a) Plain radiograph of metatarsophalangeal joint of big toe. No cortical destruction is seen.

(b) Macrotomograph, showing destruction of articular cortex and subcortical bone of base of phalanx in ioint centre. (c) Macrotomograph 15 months later, after Anturan treatment, showing that this lesion has almost healed. (a) Reproduced by permission of the Editor of Clinical Radiology (1963), 14, Fig. 12, p. 413. 


\section{Summary}

(1) Selected joints of the hands, wrists, and feet of a series of patients suffering from rheumatoid arthritis, osteo-arthritis, and gout have been examined by serial macrotomography on the Polytome.

(2) The clinical and radiological features of these patients are presented.

(3) The value of macrotomography in this type of patient is briefly discussed.

We are grateful to Dr. A. E. Read, Department of Medicine, University of Bristol, for referring Case 1 to us and to the Editor of Clinical Radiology for permission to reproduce Figures 1, 6, and 10.

\section{REFERENCES}

Carter, S. J., Martin, J. J., Middlemiss, J. H., and Ross F. G. M. (1963). Clin. Radiol., 14, 405.

Ross, F. G. M. (1963). J. Laryngol., 77, 737.

\section{DISCUSSION}

Dr. A. ST.J. Dixon (Chelsea and Kensington): I should like to congratulate the speaker on this work, but I wonder whether there was any special virtue in making these macro-films?

Dr. Ross: We found them easier to interpret if enlarged, especially in dealing with the smaller joints.

Prof. E. G. L. BYwaters (Taplow): These were very beautiful pictures, and show a very valuable advance, in technique, but they are not as informative as histological sections. In particular, I refer to some of the "cysts" which these films appeared to show, on the basal and lateral side of the thumb metacarpal in rheumatoid arthritis and osteo-arthritis as seen on section; quite a number in this situation appear histologically to be merely marrow spaces, perhaps due to remodelling in the bone consequent on this lateral shift, whereby the joint surface no longer comes into contact with opposing pressure surfaces.

Dr. G. D. KersLey (Bath): Except in one particular case, where a patient had a large number of nodules over the hands, it was quite easy to see that at some point or other the "cyst" broke through to the surface. We cannot go so far as to say, from tomograms in one plane, that these were true cysts, but it seems almost certain that they were. We find very many cases in which plain $x$ rays, when examined reasonably carefully, appear to be normal, but in which "cystic" changes and erosions are obvious on tomography.

I have been struck by one or two cases in which, even with tomography, the "cysts" of certain osteo-arthritic joints were almost indistinguishable from those in certain rheumatoid arthritic joints.

\section{La tomographie dans l'arthrite de petites articulations}

\section{RÉSUMÉ}

(1) On a examiné au moyen de la macrotomographie en série sur le Polytome les articulations choisies des mains, poignets et pieds d'une série de dix malades atteints d'arthrite rhumatismale, d'ostéoarthrite et de goutte.

(2) On décrit les caractères cliniques et radiologiques de ces malades.

(3) On discute brièvement la valeur de la macrotomographie chez ce type de malade.

La tomografía en la artritis de las pequeñas articulaciones

\section{SUMARIO}

(1) Se examinaron por macrotomografía en serie sobre el Polytome las articulaciones elegidas de manos, muñecas y pies de diez enfermos con artritis reumatoide, osteoartritis y gota.

(2) Se describen los caracteres clínicos y radiológicos de estos enfermos.

(3) Se discute brevemente el valor de la macrotomografía en este tipo de enfermo. 